Proceedings

\title{
Yellow Water to Aid Food Security- Perceptions/Acceptance of Consumers toward Urine Based Fertilizer ${ }^{+}$
}

\author{
Mustafa Nawzad Taher, Ayca Basar, Amr Mustafa Abdelrahman and Bilsen Beler-Baykal * \\ Department of Environmental Engineering, Istanbul Technical University, Ayazaga, 34469 Istanbul, Turkey; \\ mustafan90@gmail.com (M.N.T.); aycabsr@gmail.com (A.B.); a.m.abdelrahman@hotmail.com (A.M.A.) \\ * Correspondence: baykalb@itu.edu.tr; Tel.: +90-533-579-5751 \\ + Presented at the 3rd EWaS International Conference on "Insights on the Water-Energy-Food Nexus", \\ Lefkada Island, Greece, 27-30 June 2018.
}

Published: 30 July 2018

\begin{abstract}
Yellow water is a segregated domestic wastewater stream resulting from Ecological Sanitation (ECOSAN). It is mainly source separated human urine which is rich in nutrients. The potential contribution of yellow water as fertilizer to food security is considerable. The use of this potential however is related to the acceptance of the consumers towards urine based fertilizers (UBF). This work aims to assess acceptance of consumers towards UBF and urine diverting toilets (UDT) for separation of urine, through questionnaires with 444 participants from Egypt, Iraq and Turkey with different age groups, genders, educational backgrounds and occupations. The overall acceptance for UDTs and UBF was $62 \%$ and $56 \%$, respectively. All-in-all, public opinion regarding the use of UDT/UBF is promising.
\end{abstract}

Keywords: source separated human urine; public perception/acceptance; urine based fertilizers; urine diverting toilets; food security

\section{Introduction}

Food is an essential commodity to feed 7.6 billion people as of today, and global food security is a worldwide concern. Due to climate change and increasing population together with urbanization, food security is under threat. To mitigate this threat, it is urgent to develop alternative concepts to provide food security and sustainable agriculture. ECOSAN, the recent sanitation concept, is based on stream segregation of domestic wastewater at the source and claims that wastewater is not a waste to be discarded but a source to be revaluated. Among these streams, yellow water is mainly source separated human urine with a rich nutrient content: $80 \%$ nitrogen $(\mathrm{N})$, over $50 \%$ phosphorus $(\mathrm{P})$ and potassium $(\mathrm{K})$ but only $1 \%$ by volume as compared to domestic wastewater [1], and N, P and K plant nutrients that constitute fertilizers. As the nutrients in human urine are readily available to plants, urine has been suggested as an alternative fertilizer. Since the nutrients in human urine that can potentially be collected across the world constitute about $35 \%$ of the global fertilizer use [2] and the amount of nutrients excreted in urine by one person on a daily basis is equivalent to what is needed to produce one loaf of bread, the potential contribution of yellow water to food security is considerable. Urine based fertilizers (UBF) can be applied in agricultural fields either through direct or indirect routes following collection of urine at the source through urine diversion. With direct route urine will be applied onto soil after storage for pathogenic inactivation. With indirect route nutrients in urine are concentrated using processes such as adsorption/ion exchange, struvite precipitation and stripping/absorption, and then recovered nutrients are applied onto plants [3]. While there are some concerns with the direct use since urine may involve potential problems related 
to pathogens, pharmaceuticals, hormones and salinity, indirect use helps eliminate these concerns to a large extent.

Segregation of yellow water necessitates the use of special non-conventional infrastructure. Urine diverting toilets (UDT)s have been used to separate urine from fecal matter at the source of origin. There is no major difference between the use of UDTs used in urban contexts and conventional toilets and UDTs offer similar comfort except that the user has to sit on the toilet.

Public awareness is the preliminary step to provide public participation to achieve success for the implementation of new concepts, and the use of the potential embedded in urine is one of those. Since the use of UBF is closely related to the acceptance of the final users towards UDTs and products produced from crops fertilized with UBF, assessment of perceptions and acceptance of consumers for UBF, UDT and products produced is an essential step. Within that context, assessing the perceptions of a community will shed light upon possible success of this practice in large scale. There are several pieces of research in the literature which provide assessment about public perception and acceptance for UBF and UDT. For instance, in the Swiss case focused on consumers, the acceptance to eat vegetables fertilized with urine was $72 \%$, while the preference for urine as fertilizer was $80 \%$ which was higher than synthetic fertilizers [4]. In the Nigerian case focusing on local community, the acceptance to use urine as fertilizer was $8 \%$ and increased to $80 \%$ after showing a demonstration of a successful actual field, while the willingness to install UDTs after showing the demonstration was 95\% [5]. In the case of consumers in Ghana, the acceptance to buy vegetables fertilized with urine was $54 \%$ [6]. With South African home dwellers, current use of fertilizers from toilet pits was $2 \%$ while the acceptance to use their own urine as fertilizer was $53 \%$ and the acceptance to use other's urine as fertilizer was $21 \%$ [7]. In Hawaii, USA, the acceptance to install a UDT at home for free was $86 \%$ while the willingness to pay $\$ 50$ to install one was $61 \%$ [8]. In one Turkish case, the acceptance for natural fertilizers was as high as $100 \%$ and for synthetic fertilizers it was $49 \%$, while for different types of plants, direct use received $23-55 \%$ and indirect use received $68-91 \%$ [9]. In two other Turkish cases, the acceptance to use natural fertilizers was similar to each other and approaching the previous $100 \%$ with $96-98 \%$. The acceptance to use synthetic fertilizers for different types of plants was $4-22 \%$, while the acceptance to use human urine as a fertilizer varied from $50 \%$ to $82 \%$, UDTs received $81 \%$ acceptance in both cases $[2,10]$. The acceptance to install a UDT at their own homes for free was $77 \%$ while the willingness to pay extra money was 30\% [2].

The aim of this paper is to assess perceptions and acceptance of consumers towards UBF and UDT for separation of urine, through a survey with 444 participants from three different countries, namely Egypt, Iraq and Turkey, with respondents from different age groups, genders, educational backgrounds and occupations. The survey includes questions related top references about fertilizers (natural, synthetic and/or urine based); direct use and indirect use of urine; UBF application on different types of plants and landscape areas, and the use of UDTs. The paper provides an overall presentation of the results of the entire survey together with the response of each of the three countries, in a comparative mode when applicable.

\section{Materials and Methods}

Face to face and internet surveys using "Google Forms" were conducted with 444 people from Egypt, Iraq, and Turkey. The selection of the participants was made randomly without targeting a specific group. The respondents were of different age groups, genders, educational backgrounds and occupations. In addition to demographic questions, the survey consisted of 18 questions regarding former knowledge on ECOSAN/yellow water and UDTs, acceptance and willingness to use UDTs and UBF and their motivation and concerns regarding the two. Some limited information was provided about UDT and direct/indirect urine application.

As listed in Table 1, the questions were either in format of multiple-choice (MC) or Yes/No (Y/N). For questions that had one unique answer, the analysis was based on simple head counts and their respective percentages, while for those that might have more than one answer; the analysis was based on preference counts and their respective percentages. The analysis includes the results of each of the 
three countries as well as presenting the overall results of the entire survey which was done by using "Excel" spreadsheets.

Table 1. Questionnaire statements and number of answer choices.

\begin{tabular}{|c|c|c|}
\hline No. & Questionnaire Statements & $\begin{array}{l}\text { Answer } \\
\text { Choices }\end{array}$ \\
\hline 1 & Do you recognize the following terms "ECOSAN" / "Segregated Streams"? & $\mathrm{Y} / \mathrm{N}^{3}$ \\
\hline 2 & Do you recognize the term "yellow water"? & $\mathrm{Y} / \mathrm{N}^{3}$ \\
\hline \multirow[t]{2}{*}{3} & Would you accept to use UDT toilet? (Picture of UDT was given) & $3 \mathrm{MC}^{4}$ \\
\hline & (a) Yes, (b) No, (c) Not Sure & \\
\hline \multirow[t]{2}{*}{4} & What is your concern of using UDT? ${ }^{1}$ & $6 \mathrm{MC}^{4}$ \\
\hline & $\begin{array}{l}\text { (a) Unclean, (b) Expensive, (c) Unpractical, (d) Uncomfortable, } \\
\text { (f) Psychological (e) No opinion }\end{array}$ & \\
\hline \multirow[t]{2}{*}{5} & Where will you prefer using UDT? ${ }^{1}$ & $6 \mathrm{MC}^{4}$ \\
\hline & $\begin{array}{l}\text { (a) Home, (b) School, (c) University, (d) Mall, (e) Public Toilets, } \\
\text { (f) None of these }\end{array}$ & \\
\hline 6 & Do you accept to pay extra money for installing UDT toilet at your house? & $\mathrm{Y} / \mathrm{N}^{3}$ \\
\hline 7 & Do you accept to install UDT toilet for free at your house? & $\mathrm{Y} / \mathrm{N}^{3}$ \\
\hline 8 & Would you recommend using UDT to your friends? & $\mathrm{Y} / \mathrm{N}^{3}$ \\
\hline \multirow[t]{2}{*}{9} & Upon which group's recommendation would you accept to use UDTs? ${ }^{1}$ & $6 \mathrm{MC}^{4}$ \\
\hline & $\begin{array}{l}\text { (a) Celebrity, (b) Academician, (c) Athlete, (d) Family member, } \\
\text { (e) Friend, (f) Others }{ }^{2}\end{array}$ & \\
\hline 10 & Do you accept to use natural fertilizer (animal manure, etc.)? & $\mathrm{Y} / \mathrm{N}^{3}$ \\
\hline 11 & Do you accept to use synthetic fertilizer (chemicals)? & $\mathrm{Y} / \mathrm{N}^{3}$ \\
\hline 12 & Would you accept the use of Human Urine as a fertilizer? & $\mathrm{Y} / \mathrm{N}^{3}$ \\
\hline \multirow[t]{2}{*}{13} & What do you think about the application of human urine as natural fertilizer is? & $\mathrm{Y} / \mathrm{N}^{3}$ \\
\hline & $\begin{array}{l}\text { (a) Hygienic, (b) Economic, (c) Good for plants, (d) Environmentally Friendly, (e) } \\
\text { Others }{ }^{2}\end{array}$ & \\
\hline \multirow[t]{2}{*}{14} & What is your concern of using human urine as fertilizer? & $\mathrm{Y} / \mathrm{N}^{3}$ \\
\hline & $\begin{array}{l}\text { (a) Not hygienic, (b) Not economic, (c) Odor, (d) Harmful to plants, (e) Psychological, } \\
\text { (f) Others 2, (g) I don't have any concern }\end{array}$ & \\
\hline \multirow[t]{2}{*}{15} & Which form of application would you accept? (Information was given) & $3 \mathrm{MC}^{4}$ \\
\hline & (a) Direct, (b) Indirect, (c) No opinion & \\
\hline \multirow[t]{2}{*}{16} & $\begin{array}{l}\text { From the following where will you accept the use of human urine as fertilizer for green } \\
\text { areas? }{ }^{1}\end{array}$ & $7 \mathrm{MC}^{4}$ \\
\hline & $\begin{array}{l}\text { (a) Your garden, (b) Children playground, (c) School/University garden, (d) Public } \\
\text { parks, (e)Landscape, (f) Others 2 }, \text { (g) I don't accept it at all }\end{array}$ & \\
\hline \multirow[t]{2}{*}{17} & $\begin{array}{l}\text { From the following do you accept the use of human urine as fertilizer for crops } \\
\text { consumed by humans? }{ }^{1}\end{array}$ & $7 \mathrm{MC}^{4}$ \\
\hline & $\begin{array}{l}\text { (a) Cooked Vegetables (Spinach), (b) Uncooked Vegetables (Salad green), (c) Fruits } \\
\text { from trees (Apple), (d) Fruits from ground (Strawberry), (e) Cereals, (f) Others }{ }^{2},(g) \text { I } \\
\text { don't accept it at all }\end{array}$ & \\
\hline 18 & $\begin{array}{l}\text { From the following do you accept the use of human urine as fertilizer for crops used by } \\
\text { humans? }{ }^{1}\end{array}$ & $6 \mathrm{MC}^{4}$ \\
\hline
\end{tabular}

${ }^{1}$ participants were allowed to choose more than one choice. ${ }^{2}$ Participants were allowed to write their opinions on this section. ${ }^{3} \mathrm{Y} / \mathrm{N}$ : Yes or No. ${ }^{4} \mathrm{MC}$ : Multiple Choice.

\section{Results and Discussion}

\subsection{Demographic Data}

In terms of gender, the percentages of male and female participants were $58 \%$ and $42 \%$ respectively. The majority of the participants were from the young generation, ages $<20$ and $20-30$ constituting $67 \%$ of the participants. The educational level of the participants varied from no university education (Primary, secondary, and/or high school degrees only) to graduate level. $87 \%$ of 
the participants had already received or were still working for university degrees. The occupations of the participants varied widely, and the majority was engineers with $29 \%$, with $30 \%$ of this as environmental engineers. Students constituted $24 \%$ of participants. As it may be observed from Table 2 representing demographic data, the majority of the participants were young and highly educated group of the three countries. Most of the participants were from urban areas with $95 \%$, and only $5 \%$ of the participants were from rural areas.

Table 2. Demographic data of the participants.

\begin{tabular}{lllllllll}
\hline Data & No. & \% & Data & No. & \% & Data & No. & \% \\
\hline Gender & & & Educational Level & & & Occupation & & \\
\hline Male & 257 & 58 & Primary School & 5 & 1 & Academician & 43 & 10 \\
Female & 187 & 42 & Secondary School & 32 & 7 & Engineer & 127 & 29 \\
& & & High School & 20 & 5 & Teacher & 40 & 9 \\
\hline Age & & & Undgr. Student & 66 & 15 & Student & 106 & 24 \\
$<20$ & 43 & 10 & University Degree & 321 & 72 & Business \& Economics & 25 & 6 \\
$20-30$ & 253 & 57 & & & & Doctor & 32 & 7 \\
$30-40$ & 65 & 15 & Urban/Rural & & & Lawyer & 10 & 2 \\
$40-50$ & 48 & 11 & Urban area & 422 & 95 & Others & 61 & 14 \\
$50-60$ & 24 & 5 & Rural area & 22 & 5 & & & \\
$60<$ & 11 & 2 & & & & & & \\
\hline
\end{tabular}

\subsection{Use of Urine Diverting Toilets (UDTs)}

The survey started by addressing the previous knowledge of participants regarding "ECOSAN/Segregated Streams" and "Yellow Water". As shown in Figure 1, the results revealed that $82 \%$ had no knowledge of former and $66 \%$ had no knowledge about latter.

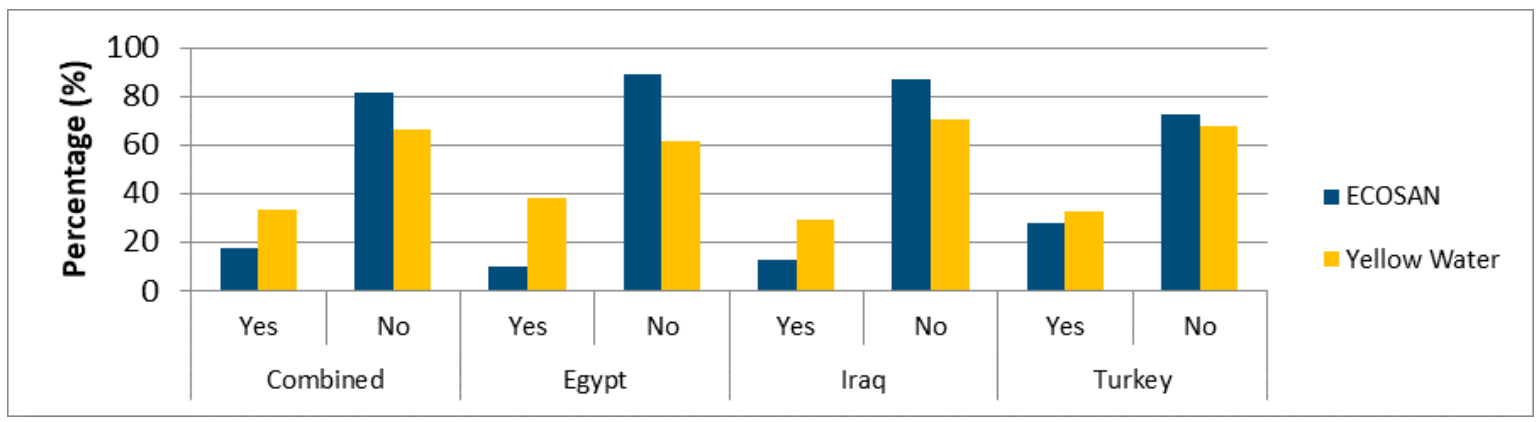

Figure 1. Knowledge about "ECOSAN/Segregated Streams" and "Yellow Water" terms.

Regarding the UDT, the questions aimed at understanding the acceptance and willingness of the people to use UDTs, to assess restrictions on the application of UDT and to reflect their concerns, as well as the most preferred locations for the installation of such toilets. Figure 2 indicates that out of the 444 participants, $63 \%$ had accepted the use of the UDT, and 13\% rejected the idea of using it completely. $24 \%$ of the participants were not sure if they will accept it or reject it, probably due to lack of knowledge about UDTs, as was shown to be very significant for UBF's in the Nigerian experience [5].

When participants were asked about their concerns regarding UDTs, the answers were distributed among the given options showing that there were no major differences between them. $25 \%$ of the answers said that the UDT application is expensive, which emphasizes the economic concern of the participants which ranked the highest. The participants think that the UDTs are unpractical by $19 \%$, unclean by $18 \%$, uncomfortable by $16 \%$, and about $15 \%$ had no specific concern. 


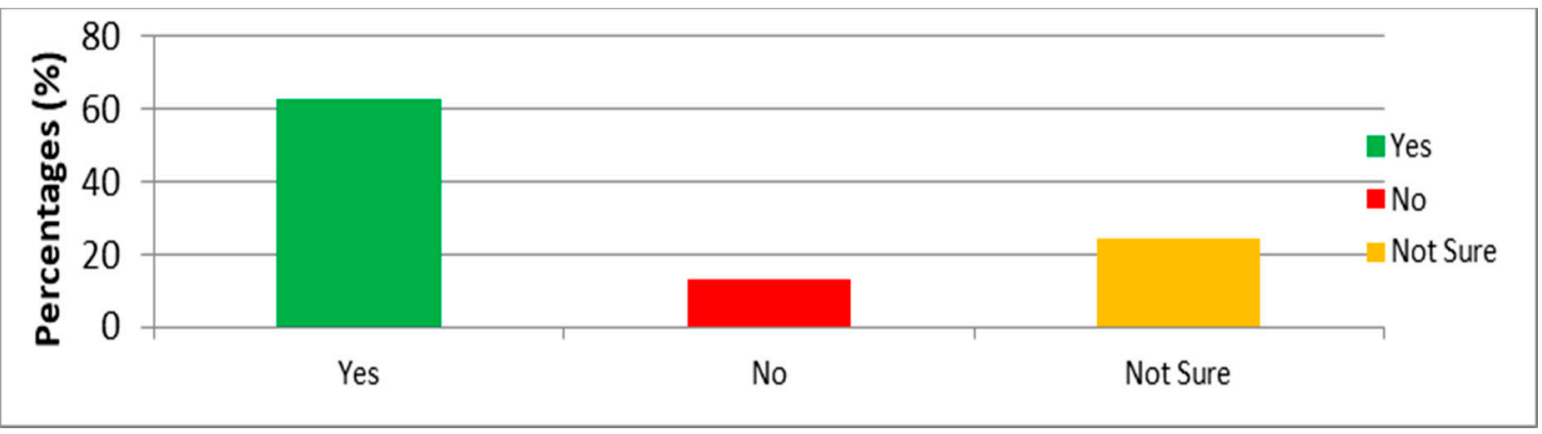

Figure 2. Acceptance and rejection of UDT.

As shown in Figure 3, there was no major variation of opinion regarding the location of installation, the percentages were: home $22 \%$, school $14 \%$, university $18 \%$, mall $16 \%$, public toilets $20 \%$, showing that there is no one specific preference for UDT installation, and that it seems possible to install the UDT in all locations questioned. The percentage of the participants who refused all was $7 \%$ overall, highest in Egypt with 11\% and lowest in Turkey at 3\%.

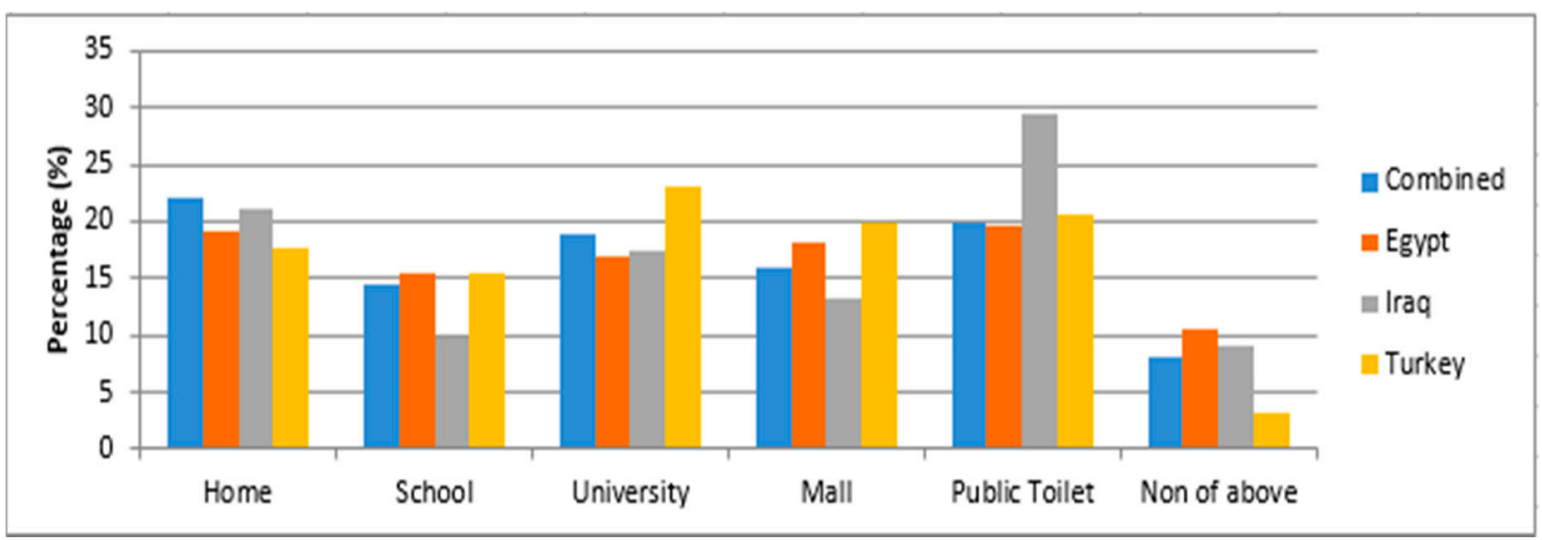

Figure 3. Preferred locations to install UDT.

When the participants had been asked the question about paying extra money to install UDT in their own houses, the response was pessimistic with $69 \%$ of refusal. However, acceptance was $72 \%$ if it is installed for free, as shown in Figure 4. This is a good reflection of the economic concerns and the probable effectiveness of economic incentives.

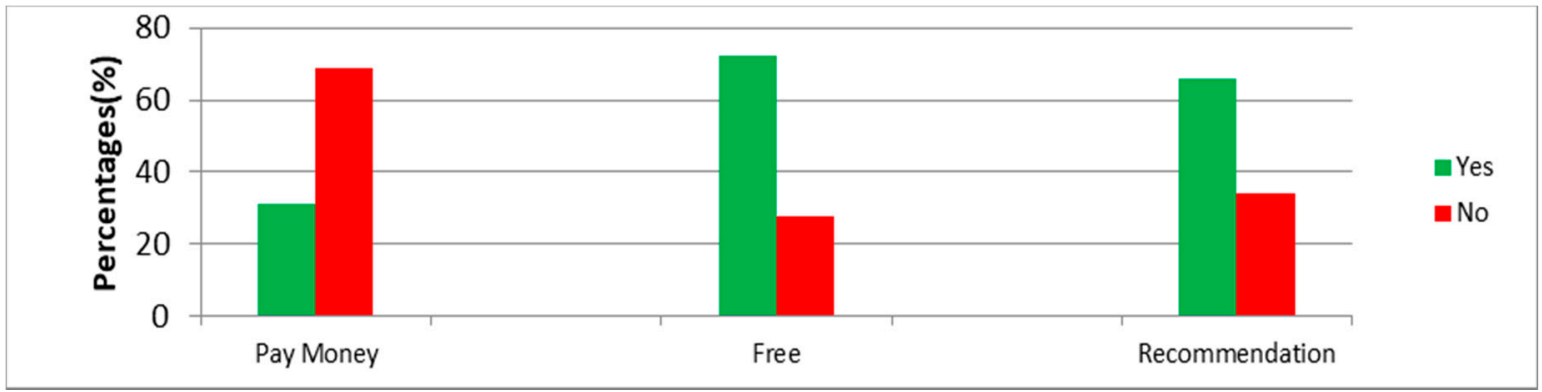

Figure 4. Paying extra money vs free installation of UDT.

$66 \%$ of the participants said that they would recommend UDTs to others, while $34 \%$ said they would not, as illustrated in Figure 4. Additionaly, 34\% of the participants said that they would be encouraged with a recommendation from an academician and from a family member by $25 \%$ each and from a friend by $24 \%$. This observation is important as it shows groups which can effect public opinion for this new practice, and it gives an indication that the participants will trust either a scientific source or considerably known person like a family member or a friend. 


\subsection{Use of Source Separated Human Urine as a Fertilizer}

Before questioning the acceptance of source separated human urine as fertilizer, the survey aimed to check the approval of natural and synthetic fertilizers. $88 \%$ of the participants approved the use of natural fertilizers, while $49 \%$ approved synthetic fertilizers, similar to the ones in the literature. Taking a look at the individual percentages for each country, the highest acceptance for natural fertilizers was from Egypt by $96 \%$, while for synthetic fertilizer the highest acceptance was from Turkey by $63 \%$. The acceptance of the source separated human urine as a fertilizer received $56 \%$ overall and was similar in the three countries as shown in Figure 5.

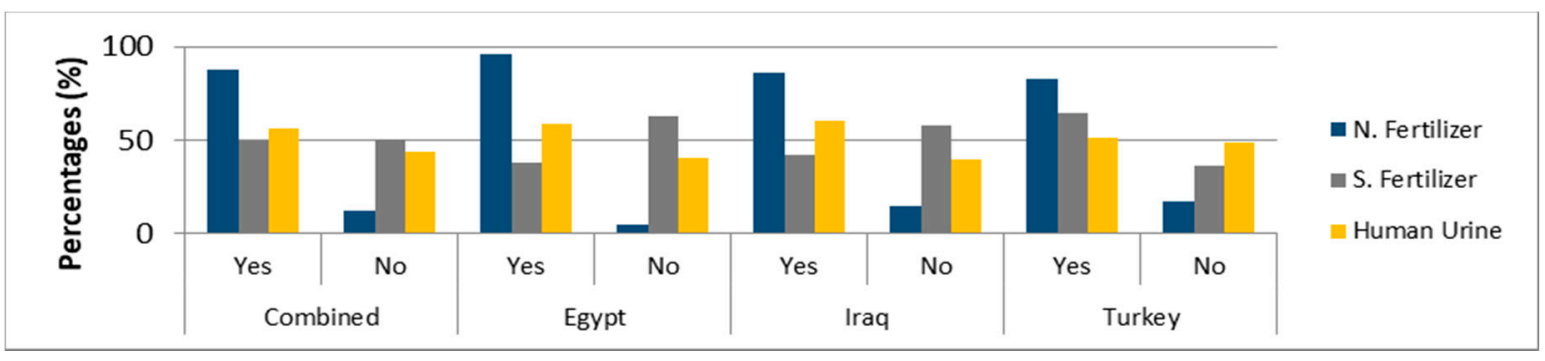

Figure 5. Acceptance of natural fertilizer, synthetic fertilizer, and source separated human urine.

The motivations and concerns of participants were investigated regarding UBF. Over $60 \%$ of the participants thought that the application of the source separated urine will come with hygienic risks, but over $90 \%$ of the participants thought that such an application will have economic benefits. Besides that, $69 \%$ and $77 \%$ of the participants thought that source separated urine will be a useful application for plants and environment, respectively. Regarding further concerns, $75 \%$ of the participants thought that odor will be accompanying source separated urine, and about $68 \%$ would have psychological concerns with such type of an application, as it is illustrated in Figures 6 and 7.The three countries showed similarity in the percentages regarding the motivations, with Egypt showing the lowest motivation in general. In terms of concerns, Turkish participants showed the lowest concern among the three countries in general.

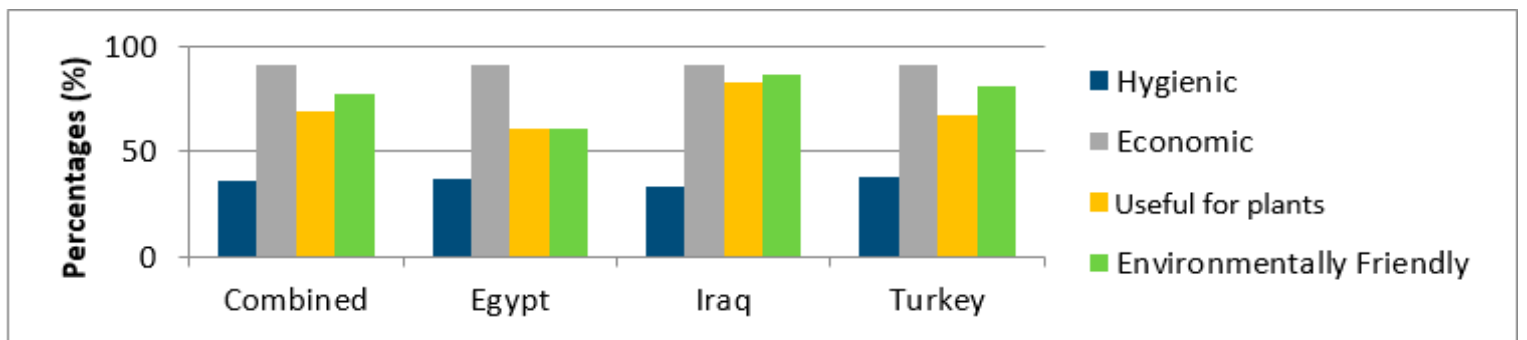

Figure 6. Motivations of the participants.

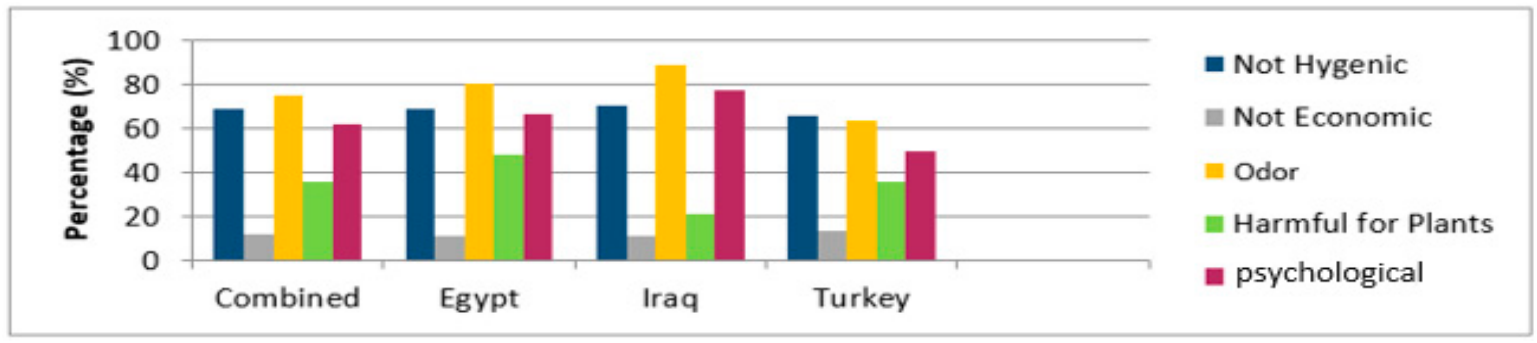

Figure 7. Concerns of the participants.

As could be expected, indirect application was preferred over direct one, as was the case with other previous surveys in the literature, with $55 \%$ for the former as opposed to $22 \%$ for the latter. About the willingness/acceptance for self-consumption of crops grown with source separated urine, the participants' attitude was checked toward two different types of crops: edible and non-edible 
(green areas and industrial plants). The participants gave approval to green areas application by 93\% distributed as shown in Figure 8, with the highest approval for landscape areas. Only 7\% said they did not approve it at all for green areas. Preferences of the participants of the three countries were similar in terms of the green areas.

The attitude of the participants regarding edible crops is illustrated in Figure 9, which shows that $82 \%$ of the participants seemed to give approval to at least one of those edible crops. The distribution regarding acceptances for different food groups is given in Figure 9. The highest approval was for cooked vegetables with $23 \%$ which again gives another indication towards hygienic concerns of the participants as was mentioned before. The only noticeable difference among the three countries was with percentage of rejection, Iraqi participants showed the highest rejection with $22 \%$ while Turkish participants rejected the use of UBF for edible crops with 7\% only.

Regarding third type (crops used in industries), the general approval was by $91 \%$ as illustrated in Figure 10, with the highest approval for the cotton by $29 \%$ followed by linen and tobacco $25 \%$ and $20 \%$ respectively. Only $9 \%$ of the participants rejected the application of source separated urine as a fertilizer for this type of crops. In Turkey, preferences showed differences as compared to the overall, linen received the highest approval (29\%) followed by cotton $(25 \%)$ and tobacco $(21 \%)$, while Iraq and Egypt were following the same preferences as the overall trend. Rejection followed a similar trend as the edible crops with highest rejection from Iraq and lowest from Turkey.

As a matter of fact, the acceptance level decreased when the crops fertilized with source separated urine was consumed or used directly by the participants themselves, and that was observed for the acceptance level of all three categories of the crops, as well as within different groups of the same category.

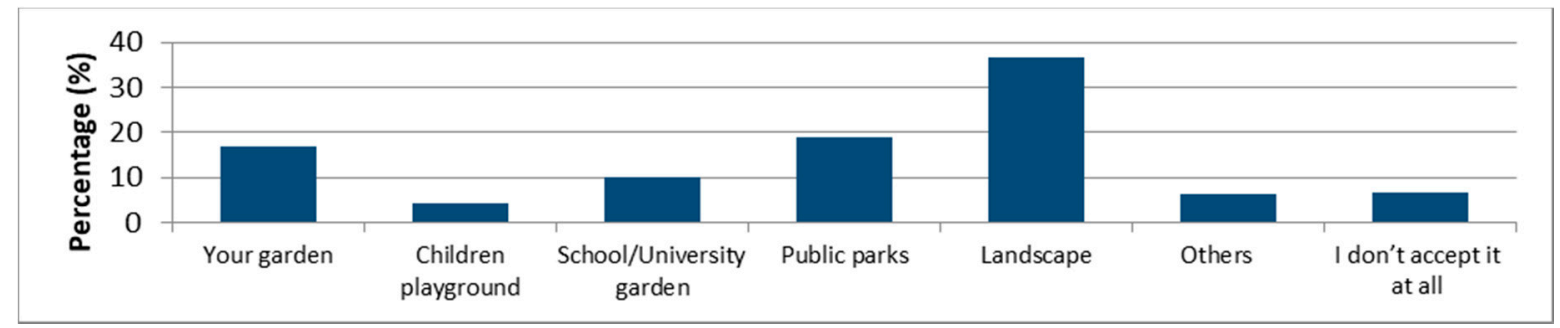

Figure 8. Preferences for green areas applications.

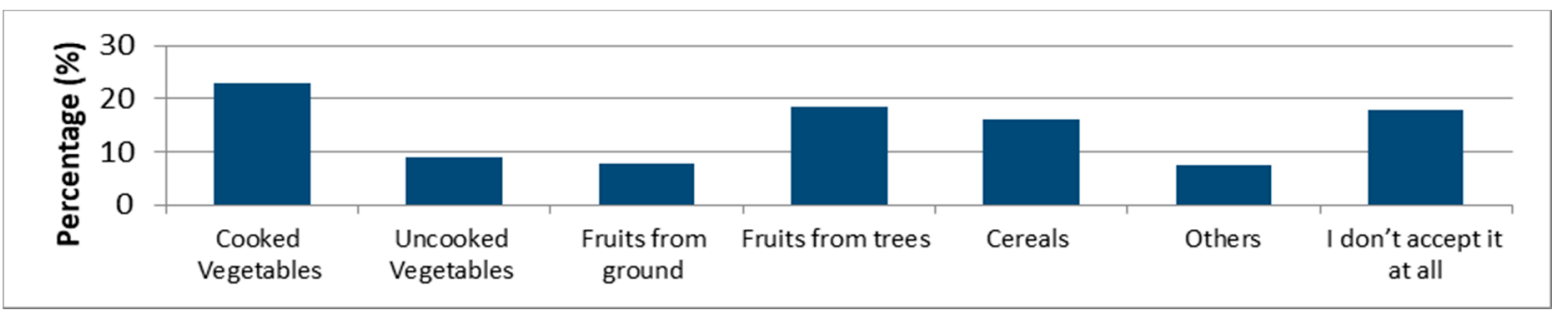

Figure 9. Preferences for edible crops applications.

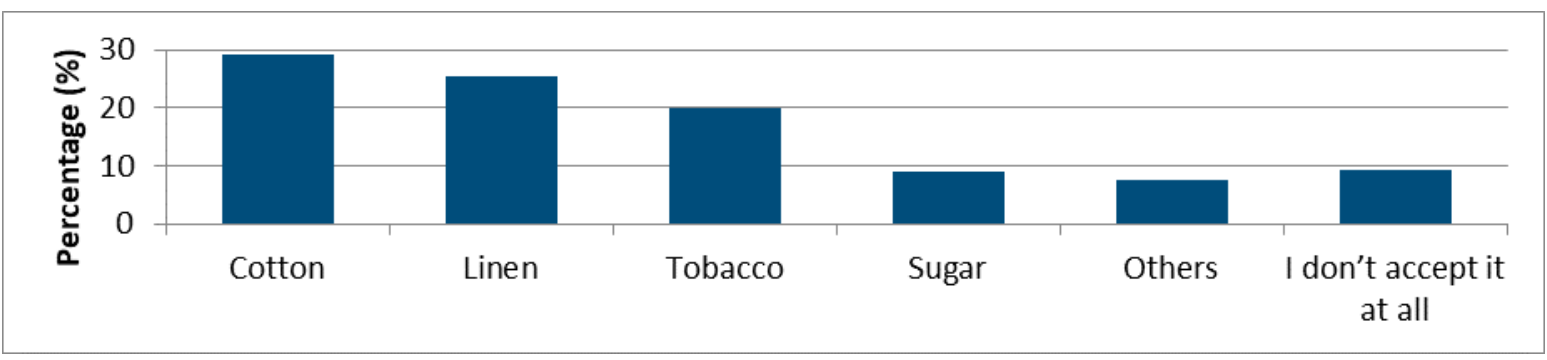

Figure 10. Preferences for industrial crops. 


\section{Conclusions}

This survey provides a background about people's attitude towards use of UDT and UBF in Egypt, Iraq and Turkey. Results have shown that $63 \%$ of the participants accepted UDT use and the highest concern was about the high price of UDT. An economic incentive in the form of free installation was observed to raise the level of acceptance to $72 \%$ as opposed to $30 \%$ when no incentive was provided. Natural fertilizers usage has received an overall $88 \%$ approval, while $49 \%$ of the participants approved synthetic fertilizers usage. The use of human urine as fertilizer received $56 \%$ acceptance overall, which shows a higher preference as compared to synthetic ones. Most of the participants had optimistic thoughts about economic benefits, while the majority of their concerns were about odor and hygienic risks. Indirect use received twice as much acceptance over direct use. Landscape use was the most highly preferred application. Cooked vegetables and cotton received the highest approvals among edible crops and industrial crops respectively. The participants accepted use of urine for cotton more than the other industrial crops.

$\mathrm{UBF}$ is a promising approach towards a sustainable future and public acceptance is a major element of this practice. Within the context of this work, it was observed there is a considerable amount of acceptance of this approach by people from three countries. Therefore, it should be taken as an indication for successful future application. The possibility of future improvement for UBF acceptance through enhanced public education and awareness raising seems high. All-in-all, public opinion regarding the use of UDT/UBF is motivating.

\section{References}

1. Beler-Baykal, B. Stream segregation in household use: A review of grey water as an alternative source of water and yellow water as an alternative source of fertilizers. Water Qual. Expo. Health 2015, 7, 27-37.

2. Allar-Emek, A.; Yıldız-Dogan, N.; Beler-Baykal, B. Public perception and acceptance of fertilizers from human urine among Turkish citizens holding university degrees. In Proceedings of the 8th International Conference on Environmental Science and Technology, Houston, TX, USA, 6-10 June 2016.

3. Beler-Baykal, B.; Dogan, G. Two stage processing options for enhancing total nutrient recovery from source separated human urine to be used as fertilizer. In Proceedings of the WEF/IWA Nutrient Removal and Recovery Conference, Denver, CO, USA, 10-13 July 2016.

4. Pahl-Wostl, C.; Schönborn, A.; Willi, N.; Muncke, J.; Larsen, T.A. Investigating consumer attitudes towards the new technology of urine separation. Water Sci. Technol. 2003, 48, 57-65.

5. Sridhar, M.K.C.; Coker, A.O.; Adeoye, G.O.; Akinjogbin, I.O. Urine harvesting and utilization for cultivation of selected crops: Trials from Ibadan, South West Nigeria. In Proceedings of the 3rd International Ecological Sanitation Conference, Durban, South Africa, 23-26 May 2005.

6. Cofie, O.; Amoah, P.; Egyir, I.; Noah, A.; Tettey-Lowor, F. Demonstration on the Use of Urine in Urban Agriculture. Report of the Sustainable Urban Water Management Improves Tomorrow's City's Health (SWITCH) Project. International Water Management Institute, 2011. Available online: http://www.switchurbanwater.eu/outputs/pdfs/W52_GEN_RPT_D5.2.4_Demonstration_on_the_use_of_u rine_in_urban_agriculture.pdf (accessed on 20 January 2018).

7. Okem, A.E.; Xulu, S.; Tilley, E.; Buckley, C.; Roma, E. Assessing perceptions and willingness to use urine in agriculture: A case study from rural areas of eThekwini municipality, South Africa. J. Water Sanit. Hyg. Dev. 2013, 3, 582-591.

8. Lamichhane, K.M.; Babcock, R.W., Jr.; Survey of attitudes and perceptions of urine-diverting toilets and human waste recycling in Hawaii. Sci. Total Environ. 2013, 443, 749-756.

9. Beler Baykal, B.; Allar, A.D.; Bozkir, E.D. A preliminary survey of the public acceptance of the use of human urine as fertilizer in Turkey. In Proceedings of the 3rd International Congress "Wastewater in Small Communities towards the Water Framework Directive and the Development Goals, Sevilla, Spain, 25-28 April 2011. 
10. Yıldız-Dogan, F.N.; Shihab, M.S.; Citak, F.T.; Beler-Baykal, B.; Pasaoglu, M.E.; Ozturk, A. A preliminary survey of public willingness and acceptance of segregation and use of human-urine as fertilizer in Turkey. In Proceedings of the 2nd International Conference on Sustainable Agriculture and Environment, Konya, Turkey, 30 September-3 October 2015.

(C) 2018 by the authors. Licensee MDPI, Basel, Switzerland. This article is an open access article distributed under the terms and conditions of the Creative Commons Attribution (CC BY) license (http://creativecommons.org/licenses/by/4.0/). 